\title{
Mid-term progressive loosening of hydroxyapatite-coated femoral stems paired with a metal-on-metal bearing
}

\author{
Trevor Gascoyne ${ }^{1}$, Bryan Flynn², Thomas Turgeon 2,3 and Colin Burnell ${ }^{2,3^{*}}$
}

\begin{abstract}
Background: Several hydroxyapatite (HA)-coated femoral stems from a single manufacturer were identified to have aseptically loosened at mid-term follow-up despite prior radiographic appearance of osseointegration. Possible causes and associated risk factors for stem loosening were explored through radiographic review and implant retrieval analysis.

Methods: Forty-six retrieved hip stems (Corail, DePuy-Synthes) were identified and grouped by bearing type: metal-on-metal (MoM), metal-on-polyethylene, and ceramic-on-ceramic. Stem lucency was graded on postoperative radiographs up to the time of revision. Stems were examined for stripping of the HA coating, taper corrosion, and bearing wear in metal-on-metal cases. Patient demographics, implant design features, and perioperative data were collected from electronic databases and patient charts.

Results: Aseptic loosening occurred in 37\% of cases examined. MoM bearings were associated with 7.25 times greater risk of loosening compared to other bearing types. Stem radiolucency was more prevalent for MoM cases and, although not statistically significant, demonstrated progressive lucency. Taper corrosion appeared more severe for MoM cases and correlated with proximal stem radiolucency. Removal of the HA coating from the stems was associated with both taper corrosion and MoM bearing wear. Length of implantation was a confounding factor for the MoM cases.

Conclusion: This study has demonstrated a high risk of mid-term loosening of previously osseointegrated HA-coated femoral stems when paired with a MoM bearing. The mechanism of loosening appears progressive in nature and related to the MoM bearing, possibly interacting with the HA coating. If such loosening is recognized early, rapid revision may allow for retention of the femoral stem.
\end{abstract}

Keywords: Hip arthroplasty, Aseptic loosening, Metal-on-metal, Hydroxyapatite, Radiolucency, Wear

\section{Background}

Long-term survival of total hip arthroplasty (THA) requires excellent fixation between the host bone and the prosthesis. This fixation can be achieved via cement, bone in-growth, or bone on-growth. The latter can be promoted through the use of bone growth promoting substances, such as hydroxyapatite (HA). HA is a naturally occurring mineral found within bone composition, and its presence on the femoral component supports osseointegration of the stem $[1,2]$. While primary stability of the femoral stem in cementless THA models depends on a

\footnotetext{
* Correspondence: cburnell@cjrg.ca

${ }^{2}$ Concordia Joint Replacement Group, 310-1155 Concordia Avenue, Winnipeg, Manitoba R2K 2M9, Canada

${ }^{3}$ Department of Surgery, University of Manitoba, Winnipeg, Manitoba, Canada Full list of author information is available at the end of the article
}

press fit between the bone and femoral component, longterm stability requires osseointegration of cancellous bone to the HA-coated stem [3]. Hydroxyapatite-coated femoral stems demonstrate high clinical success rates $[1,4]$; however, some concerns remain over the resorption of HA and delamination of $\mathrm{HA}$ from the stem which can lead to loosening of the implant [5].

In metal-on-metal (MoM) hip arthroplasty, bearing surfaces of the femoral head and acetabular liner are manufactured with high precision to allow fluid-film lubrication to minimize wear. Despite this design, both patient and implant-specific factors have been identified that can lead to significant bearing wear with production of large quantities of cobalt (Co) and chromium $(\mathrm{Cr})$ wear particles and ions that can have local and systemic

(c) The Author(s). 2019 Open Access This article is distributed under the terms of the Creative Commons Attribution 4.0 International License (http://creativecommons.org/licenses/by/4.0/), which permits unrestricted use, distribution, and 
effects [6]. Metal wear particles induce an inflammatory response which can cause damage to surrounding soft tissue and bone $[7,8]$ resulting in pain, loss of function, and often revision arthroplasty [9]. Beyond local reactions, high systemic metal ion concentrations have been associated with poor osseointegration of the femoral stem. Shah et al. showed that high $\mathrm{Co}$ and $\mathrm{Cr}$ ions decrease osteoblastic activity and alkaline phosphatase activity, both important processes of bone growth and development [10]. Metal ions also have a direct negative effect on HA by binding into the HA crystal in place of calcium and inhibiting the mineralization process [11]. These deleterious effects of metal ions reportedly discourage initial osseointegration processes; however, the mid- to long-term effects on bone-HA fixation are not known and numerous confounding factors may also be of direct influence.

As a result of the poor clinical performance of MoM THAs, most manufacturers have eliminated MoM as a bearing option corresponding to steep decline in their use since 2008 [12, 13]. However, many tens of thousands of patients still have functioning MoM THAs and may yet be affected by the long-term effects of these generally poor performing implants.

Several HA-coated femoral stems were identified through the implant retrieval analysis program at the Orthopaedic Innovation Centre which had clinically loosened after several years of appearing radiographically osseointegrated. We hypothesized that these cases may be associated with metal particle generation from the MoM articulation or from corrosion of the head-neck taper and subsequent depletion of the HA coating on the femoral stem. Other possible factors of mid-term HA-coated femoral stem loosening, such as stress shielding, were not examined in this study.

This study was undertaken to examine the possible causes and associated risk factors for mid-term (3-7 years post-surgery) aseptic loosening of HA-coated femoral stems and to detail their clinical manifestation through radiographic and implant retrieval analysis.

\section{Methods}

\section{Clinical data}

This study is a retrospective analysis of patient charts, radiographs, and retrieved implants of a single femoral stem design, Corail ${ }^{\circ}$ (DePuy-Synthes, Warsaw, IN). All HAcoated femoral stems were extracted from a regional implant retrieval database, resulting in a total of 46 retrievals. Research ethics approval was granted by the local review board (H2013:325, University of Manitoba). All retrieved implants were revised between 2007 and 2015 and consisted of 14 standard and 32 collared designs. Three study groups were created based on bearing type: metal-on-metal (MoM; $n=10)$, metal-on-polyethylene (MoP; $n=24)$, and ceramic-on-ceramic $(\mathrm{CoC} ; n=12)$. Patient data was collected for all retrievals, including age at primary surgery, length of implantation, reasons for revision, body mass index, femoral head offset, implant sizes, and head-neck taper size. The dataset generated from this study is available from the corresponding author on reasonable request.

\section{Radiographic review}

All available post-operative radiographs were examined by a fellowship-trained arthroplasty surgeon (BF) for evidence of radiolucent lines around the femoral stem. The width and location of each lucent line were documented according to femoral Gruen zones for all available radiographs of each patient [14]. The incidence, location, and width in millimeters of radiolucent lines were summed for each follow-up radiograph and each case examined for evidence of progression (Fig. 1).

\section{Retrieval analysis}

Retrievals were analyzed in detail for evidence of taper damage, HA coating loss (Fig. 2), and bearing wear. Femoral head-neck taper surfaces were qualitatively graded for corrosion following the Goldberg method [15]. Removal of HA from the femoral stem was graded $0-3$ based on the observed area of HA coating loss: $0=$ no HA removal, $1=1-33 \%$ HA removal, $2=34-66 \%$ HA removal, and $3=67-100 \%$ HA removal. The location of HA removal was defined proximally and distally as it appeared from radiographic analysis that stem loosening progressed in a top-down fashion.

Bearing wear and taper corrosion damage was measured only on MoM retrievals, as insignificant amounts of wear or corrosion were noted in the $\mathrm{CoC}$ and $\mathrm{MoP}$ groups and the quantification of metal debris released in vivo was of prime interest to this study. Measurement of the taper surfaces (head and neck independently) was performed with a coordinate measurement machine (CMM, Zeiss Prismo, etc) following the ASTM F3129 [16] standard. Virtual models of each tapered surface were created based on high-density point scans $(<0.1$ $\mathrm{mm}$ point spacing), and material removal (corrosion) was computed using a Boolean subtraction with the ideal "as manufactured" geometry of the taper surface.

In a similar fashion, bearing wear was measured on both the head and liner of all MoM retrievals, except with a maximum point spacing of $0.25 \mathrm{~mm}$, due to the larger surface area of the bearings. Virtual models were created as were perfect spheres to represent the "as manufactured" surface, based on the method described by Hoffmann and Pfirrmann [17]. In short, this method involves the truncation of points within the worn regions of the bearing based on a histogram of radial distances of every measured point. By removing points in the worn regions, an idealized sphere can be created that is best fit to the remaining surface of the bearing, assumed to be largely unworn. Volumetric bearing wear 

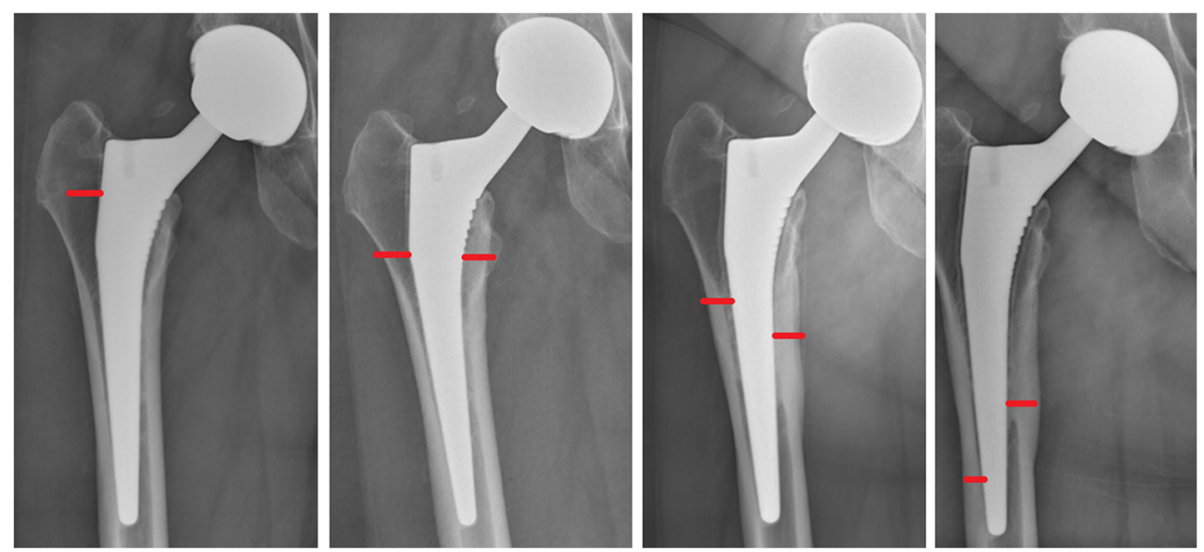

Fig. 1 Example case of progressive radiolucency around a Corail stem with a metal-on-metal bearing over a period of 4 years. Red horizontal lines indicate the depth of radiolucency on the medial and lateral sides of the stem

was computed using a Boolean subtraction between the measured surface and the ideal sphere.

\section{Statistical analysis}

Statistical analysis was performed using SAS (Statistical Analysis Software v9.3, Cary, NC). Analysis of variance was applied to test differences between bearing groups. Pearson's correlations were established between patient and implant variables. Fisher's exact test was used to calculate odds ratios and relative risk of MoM THR for aseptic loosening. Linear regression was applied to radiographic data to determine the rate of progression of radiolucency. Statistical significance was set at $p<0.05$.

\section{Results}

\section{Clinical data}

Aseptic loosening occurred in 17 of 46 cases that were examined (Table 1). Metal-on-metal bearings were associated with increased risk of aseptic loosening (odds ratio 7.25, $95 \%$ CI 1.54-34.10, $p=0.020$ ). Femoral head size, head offset, collared femoral stem, and patient age were not associated with aseptic loosening $(p>0.05)$. Mean time to revision for MoM was 4.9 years (range 3.0-7.0) compared to 1.6 years (range $0.1-9.3$ ) for other bearing couples $(p=$ 0.004 ). Body mass index was not statistically different between bearing groups nor between patients having a MoM articulation and revised for aseptic loosening versus the remainder of the cohort $(p=0.844)$.

\section{Radiographic evaluation}

Radiolucency surrounding the proximal stem region was more prevalent in the MoM group compared to $\mathrm{CoC}$ and MoP (Table 2). However, this difference did not reach statistical significance. Presence and thickness of proximal radiolucent lines in all available radiographs were assessed for 9 of $10 \mathrm{MoM}, 10$ of $12 \mathrm{CoC}$, and 17 of

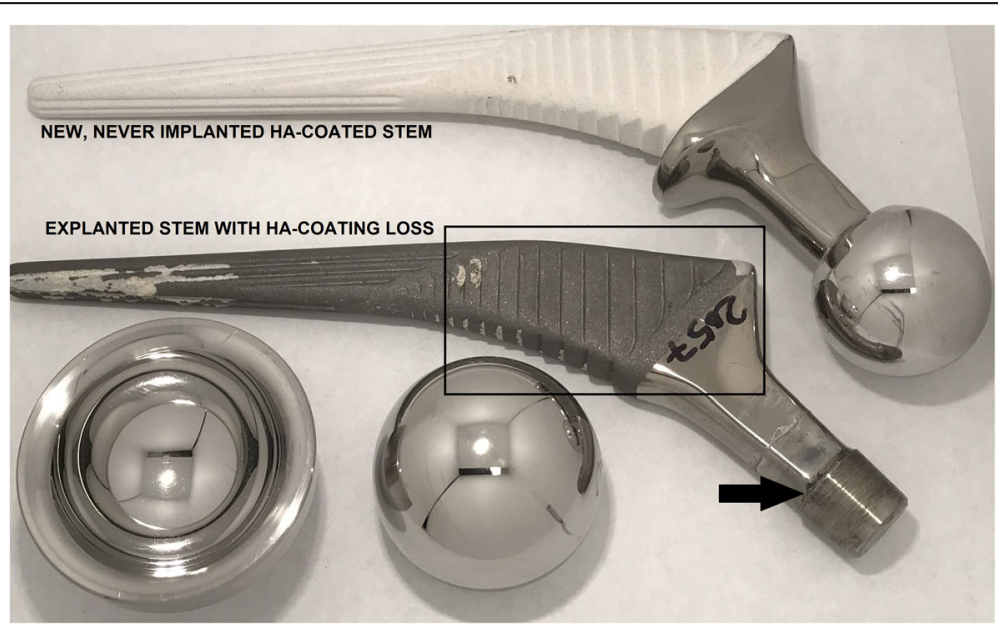

Fig. 2 Example case of HA coating removal on an explanted Corail stem with metal-on-metal bearing adjacent to an "as manufactured" Corail stem with intact HA coating. Arrow indicates the area of taper corrosion. Rectangle indicates the proximal region of the stem 
Table 1 Patient demographics and reasons for revision separated by bearing group

\begin{tabular}{|c|c|c|c|c|c|c|c|}
\hline Bearing & N & Collared stems & Age (SD) & Implantation time (SD) years & Gender & $\mathrm{BMI}(\mathrm{SD}) \mathrm{kg} / \mathrm{m}^{2}$ & Reasons for revision \\
\hline MoM & 10 & 0 & $52(12)$ & $4.9(1.3)$ & $5 \mathrm{M}: 5 \mathrm{~F}$ & $30.9(4.0)$ & $\begin{array}{l}\text { Aseptic loosening (7) } \\
\text { Periprosthetic fracture (2) } \\
\text { High metal ions (1) }\end{array}$ \\
\hline $\mathrm{CoC}$ & 12 & 5 & $58.9(6.4)$ & $1.8(1.7)$ & $6 \mathrm{M}: 6 \mathrm{~F}$ & $36.3(13.2)$ & $\begin{array}{l}\text { Infection (5) } \\
\text { Aseptic loosening (4) } \\
\text { Periprosthetic fracture (2) } \\
\text { Instability/malposition (1) }\end{array}$ \\
\hline MoP & 24 & 9 & $71.6(11.6)$ & $1.2(1.6)$ & $11 \mathrm{M}: 13 \mathrm{~F}$ & $31.7(7.0)$ & $\begin{array}{l}\text { Periprosthetic fracture (9) } \\
\text { Infection (8) } \\
\text { Aseptic loosening (6) } \\
\text { Dislocation (1) }\end{array}$ \\
\hline
\end{tabular}

24 MoP patients with their latest radiographic follow-up occurring at 49.0, 18.8, and 20.5 months after index surgery, respectively. Collared stems were not associated with radiolucency of the proximal stem $(p=0.637)$. Proximal radiolucency was found to advance at a mean rate of $0.9 \mathrm{~mm} /$ year in the MoM group.

\section{Retrieval analysis}

The presence and observed severity of taper corrosion was significantly higher in the MoM group compared to all others (Table 2). Proximal and distal HA coating removal was similarly greater in the MoM group; however, this was not statistically significant. Stem design (collared or non-collared) was not associated with HA coating removal $(p=0.267)$.

Removal of proximal HA coating was strongly associated with taper corrosion score and mildly associated with the total measured metal that was released from the THA (Table 3). Proximal radiolucency also showed weak correlation with taper corrosion score, yet did not display a statistically significant association to proximal HA coating loss. Implantation period was found to correlate significantly with HA coating removal and radiolucency (both proximal and distal) as well as taper corrosion score.

Measured bearing wear in the MoM group averaged $3.3 \mathrm{~mm}^{3}$ cumulative for heads and liners, with the majority of wear occurring on the femoral head (Table 4). Similarly, taper corrosion damage (volume) occurred primarily on the femoral head taper with a mean of 1.80 $\mathrm{mm}^{3}$ cumulative material removal (Table 4). Total metal release was correlated to proximal HA coating removal in the MoM group $(R=0.794, p=0.011)$.

\section{Discussion}

Despite improvements in bearing technology, aseptic loosening remains a leading cause for revision hip arthroplasty [18]. Promising wear simulator data for MoM has not translated clinically into improved survivorship, and results of the DePuy Pinnacle MoM THA have been varied. Some authors have noted good midterm survivorship from $97.0-99.4 \%$ at $5-7$ years [19-22]. Others have found much worse survival ranging from $92.8 \%$ at 7 years [23], $88.9 \%$ at 8 years [24], to $83.6-86 \%$ at 9 years $[25,26]$. Ten-year cumulative percentage probability of revision reported in the Australian and UK national joint registries for the Corail stem and Pinnacle cup is $3.2-4.9 \%$ for conventional bearings vs $11.7-14.6 \%$ for MoM. Our results for Corail Pinnacle MoM suggest taper corrosion is a factor in the loosening of a fully HA-coated stem that has previously shown excellent survivorship with other bearings such as MoP, CoP, and CoC $[27,28]$.

A recent publication by Buttaro et al. described a similar phenomenon with this same stem design presenting with "metaphyseal debonding" at a mean of 36 months from surgery. Their case-control study found association with increased BMI and the use of hard-on-hard bearing surfaces (both ceramic-on-ceramic and MoM) [29]. In contrast, our study did not find patient variables, including $\mathrm{BMI}$, to be associated with loss of HA coating, nor were ceramic-on-ceramic bearings found to undergo HA coating loss. Buttaro et al. were only able to assess 6 implants of the 18 cases identified, all six of which were either ceramic-on-ceramic or ceramic-on-polyethylene. Four of the 6 retrieved stems demonstrated loss of the

Table 2 Retrieval analysis and radiographic evaluation for each bearing group

\begin{tabular}{|c|c|c|c|c|c|}
\hline \multirow{2}{*}{$\begin{array}{l}\text { Bearing } \\
\text { group }\end{array}$} & \multirow{2}{*}{$\begin{array}{l}\text { Goldberg corrosion } \\
\text { score }(0-3 \text { scale) }\end{array}$} & \multicolumn{2}{|c|}{ HA coating removal (0-3 scale) } & \multicolumn{2}{|c|}{ Mean thickness of radiolucent lines at latest follow-up } \\
\hline & & Proximal & Distal & Proximal (Gruen zones 1 and 7) & Distal (Gruen zones 3, 4, and 5) \\
\hline MoM & $2.1(0.8)^{*}$ & $2.6(0.5)$ & $2.1(0.9)$ & $2.9(1.7)$ & $0.4(1.3)$ \\
\hline $\mathrm{CoC}$ & $0.8(0.9)$ & $1.4(0.8)$ & $1.7(0.9)$ & $1.7(1.6)$ & 0 \\
\hline MoP & $0.4(0.9)$ & $1.0(1.0)$ & $0.8(0.9)$ & $1.5(1.7)$ & $0.6(1.5)$ \\
\hline
\end{tabular}

"Statistical significance $(p=0.001)$ 
Table 3 Statistically significant correlations between clinical, radiographic, and retrieval variables for all bearing groups

\begin{tabular}{llll}
\hline Variable & Variable 2 & $R$ & $p$ value \\
\hline Implantation period & HA coating removal (proximal) & 0.643 & $<0.001$ \\
& HA coating removal (distal) & 0.597 & $<0.001$ \\
& Goldberg score & $0.529<0.001$ \\
& Radiolucency (proximal) & 0.359 & 0.034 \\
& Radiolucency (distal) & 0.351 & 0.039 \\
HA removal (proximal) & HA Removal (distal) & $0.539<0.001$ \\
& Goldberg score & $0.586<0.001$ \\
Goldberg score & Radiolucent lines (proximal) & 0.357 & 0.048 \\
\hline
\end{tabular}

proximal HA coating, but no analysis of the condition of the taper was discussed in the publication.

We found the presence and observed severity of taper corrosion to be associated with aseptic loosening of HAcoated femoral stems in a relatively small number of samples. The predominant mechanism of taper corrosion is thought to be mechanically assisted crevice corrosion [15]. Other contributing factors include use of dissimilar alloys [30], taper size and design [31], head size and length [32], stem offset [33], flexural rigidity of the stem neck [34], intraoperative contamination with blood or fluid, assembly force [35], and length of implantation [33, 36]. The Corail taper with its short, roughened surface may be particularly prone to corrosion [37]. Interestingly, MoP and $\mathrm{CoC}$ had no difference in corrosion scores. Dissimilar metals alone fail to account for the difference seen among the MoM as the taper, and $\mathrm{CoCr}$ head of the MoP group had little corrosion, although this may be explained by their shorter implantation time [32].

Corrosion score was also positively correlated with proximal HA loss. All retrieved MoM stems in our study had significant proximal HA loss (grade 2 or
3), with six out of seven stems having failed for aseptic loosening also showing a similar degree of HA loss. The proposed mechanisms of HA loss in the literature include delamination from the metal substrate, dissolution into extracellular fluid, and cellmediated resorption. Based on an autopsy retrieval study of HA-coated stems, Bauer et al. suggested osteoclastic resorption was the primary mode of HA resorption, assisted by enzymatic breakdown common to bone remodeling [38]. This process may be enhanced by corrosion byproducts that act as potent activators of macrophage-induced osteolysis [39]. Additionally, delayed-type hypersensitivity reactions have been implicated in aseptic osteolysis seen in MoM due to metal-induced lymphocytes releasing cytokines to shift the balance in favor of osteoclastic resorption [40]. Three of the MoM cases that failed for aseptic loosening in our series had tissue pathology results available. The tissue analyses were consistent with mild to moderate hypersensitivity reaction with moderate ALVAL scores (6, 7, and 7), suggesting this may have contributed to stem loosening.

Another possible explanation relating proximal HA loss to taper corrosion is that HA can be dissolved in acidic solutions, as demonstrated in dentistry literature [41]. While the $\mathrm{pH}$ of the joint space is more neutral compared to that of the mouth, it is feasible that it is locally altered by corrosion and wear products. Cobalt chromium and titanium alloys are biocompatible metals primarily because when in contact with oxygen, they form a protective surface film of oxidized metal rendering it non-reactive. Mechanical removal of this layer either by taper micromotion or bearing wear results in immediate reformation of the oxide layer with nearby oxygen atoms from water molecules. This oxidation reaction creates free $\mathrm{H}^{+}$ions which increase the acidity of the surrounding environment. Milosev et al. measured

Table 4 Bearing wear and taper corrosion volumes measured on retrieved MoM bearings

\begin{tabular}{lllllll}
\hline $\begin{array}{l}\text { MoM } \\
\text { patient }\end{array}$ & $\begin{array}{l}\text { Head wear } \\
\left(\mathrm{mm}^{3}\right)\end{array}$ & $\begin{array}{l}\text { Liner wear } \\
\left(\mathrm{mm}^{3}\right)\end{array}$ & $\begin{array}{l}\text { Taper corrosion } \\
\text { score }\end{array}$ & $\begin{array}{l}\text { Head corrosion } \\
\text { volume }\left(\mathrm{mm}^{3}\right)\end{array}$ & $\begin{array}{l}\text { Neck corrosion } \\
\text { volume }\left(\mathrm{mm}^{3}\right)\end{array}$ & $\begin{array}{l}\text { Total metal } \\
\text { release }\left(\mathrm{mm}^{3}\right)\end{array}$ \\
\hline Pt 1 & 1.76 & - & - & 0.46 & 0.20 & 2.42 \\
Pt 2 & 1.14 & - & 2 & 0.15 & 0.33 & 1.62 \\
Pt 3 & 0.78 & 0.40 & 1 & 0.71 & 0.50 & 2.39 \\
Pt 4 & 8.77 & 0.50 & 2 & 1.13 & 0.31 & 10.71 \\
Pt 5 & 0.84 & 0.15 & 3 & 7.10 & 0.25 & 8.34 \\
Pt 6 & 1.63 & 0.62 & 3 & 1.23 & 0.15 & 3.63 \\
Pt 7 & 1.35 & 0.07 & 1 & 0.21 & 0.17 & 1.80 \\
Pt 8 & 2.01 & 0.82 & - & 0.87 & 0.30 & 3.99 \\
Pt 9 & 9.85 & 0.32 & 2 & 0.71 & 0.72 & 11.60 \\
Pt 10 & 1.16 & 0.18 & 3 & 5.40 & 0.2 & 6.93 \\
Mean (SD) & 2.93 (3.40) & $0.38(0.26)$ & $2.1(0.8)$ & $1.80(2.41)$ & $0.31(0.18)$ & $5.34(3.77)$ \\
\hline
\end{tabular}


the $\mathrm{pH}$ of osteoarthritic synovial fluid, compared it to those with metal hip and knee arthroplasty components, and noted a small but significant decrease in $\mathrm{pH}$ in the arthroplasty group [42]. Inflammatory conditions such as rheumatoid arthritis and septic arthritis have also been found to lower synovial fluid $\mathrm{pH}$. Willert et al. measured the $\mathrm{pH}$ at the interface of 17 titanium alloy stems at time of revision noted to have signs of corrosion and found 7 stems had sub-physiologic levels dropping as low as 2.2 [43]. Lowering of local $\mathrm{pH}$ by continual reoxidation of $\mathrm{CoCr}$ alloy on various surfaces of the THA, and specifically the taper, can therefore potentially contribute to dissolution of the HA coating and aseptic loosening.

A further explanation for stem loosening is increased particulate debris from bearing wear, which has been found in some MoM implants that have higher risk of mid-term aseptic loosening. When functioning well, MoM bearings are extremely wear resistant; however, they are less tolerant for implant malposition and the smaller size and subsequent greater surface area of wear debris has high bioactivity and cytotoxicity. Further, smaller cup size has been shown to have a higher risk of wear in MoM bearings as the corresponding metal insert is thinner with higher likelihood of deformation when engaged in the shell taper. The $50 \mathrm{~mm}$ and $52 \mathrm{~mm}$ outside diameters of $36 \mathrm{~mm}$ liners (wall thickness of $7 \mathrm{~mm}$ and $8 \mathrm{~mm}$ ) have demonstrated significantly increased rates of revision in the literature [25]. In our series, liner wall thickness ranged $7 \mathrm{~mm}$ up to $12 \mathrm{~mm}$, with one sample at $7 \mathrm{~mm}$ and two samples at $8 \mathrm{~mm}$. Insufficient bearing clearance has also been implicated as a possible cause for premature failure of MoM THAs [25]. Reduced clearance increases likelihood and severity of bearing wear on MoM THAs but may also increase the toggling torque on the head-neck taper. Micromotion of the head-neck taper initiates mechanically-assisted crevice corrosion, a well-described process of taper corrosion and subsequent metal debris release [15]. While increased torque-induced stem micromotion may lead to failure of initial press fit and osseointegration as suggested in Pilliar et al., [44], it does not seem to explain the progressive loosening of previously well-fixed stems seen in the current series.

Higher cup inclination angle in MoM bearings [45] has been shown to influence wear; however, this was unlikely a factor in our study as mean cup inclination of the $7 \mathrm{MoM}$ hips that failed for aseptic loosening with available $\mathrm{x}$-rays was $42^{\circ}$ (range $39-47^{\circ}$ ). Reinisch et al. found no evidence of increased bearing wear among 22 single manufacturer MoM implants with $28 \mathrm{~mm}$ heads revised for early (12-59 months) aseptic loosening, suggesting this process can occur under normal bearing wear settings [46]. Langton et al. also found 6 cases of failed MoM with well-functioning bearing surfaces and described significantly worn taper junctions as the cause [47]. This finding has been confirmed in a retrospective cohort study examining mid-term revisions of the pinnacle MoM bearing paired with Corail or S-ROM stems showing failure from the taper junction was more common than at the bearing surface [25]. The MoM bearing wear in our study was similarly found to be low and within the normal range of reported values for this articulation [25].

Among the nine MoM hips that had 2 or more $\mathrm{x}$ rays available for review, radiolucency progressed from proximal to distal at a mean rate of $0.9 \mathrm{~mm} /$ year. None of the cases saw progression stop until time of revision. If radiolucency progression is related to ongoing taper corrosion that predictably leads to mid-term aseptic loosening, then this represents both an early warning sign and a potential therapeutic window. If recognized early when the stem remains well fixed, removing the source of corrosion may salvage the stem, limit soft tissue damage, and avoid the morbidity of more extensive revision. A recent systematic review identified nine studies examining the treatment of hip implant failures secondary to taper corrosion with the majority being treated with stem retention and exchange to a ceramic head with titanium sleeve [48]. Although follow-up was short (1-36 months), the majority of patients had resolution of their symptoms.

Limitations of this study include the small sample size available, $\mathrm{x}$-ray availability in only a subset, varying demographics between the patient groups (age, demand on the implant, and potentially activity level), variation in implant dimensions and designs, and longer implantation time in the MoM group which biases radiolucency, HA coating removal, and taper corrosion. The observed mid-term loosening, however, is unexpected in a stem with good, lengthy clinical track record.

\section{Conclusion}

Our retrieval study of a fully HA-coated stem from a single manufacturer showed a higher risk of mid-term aseptic loosening when paired with a MoM bearing. Loosening was correlated with the presence and severity of taper corrosion which was significantly higher with MoM compared to other bearing groups. Taper corrosion scores were also correlated with HA removal from the stem. This may be related to a cell-mediated response, lowering of local $\mathrm{pH}$, or both. Radiolucency progressed at an average rate of $0.9 \mathrm{~mm} /$ year until the time of revision. Corrosion should be considered as a cause of aseptic loosening of fully HA-coated stems, and if recognized early, revision is recommended. 


\section{Abbreviations}

BMI: Body mass index, the ratio of a person's body weight in kilograms versus their height in meters (weight/height ${ }^{2}$ ); CoC: Ceramic-on-ceramic, refers to the bearing materials of the ball and socket joint of the artificial hip; HA: Hydroxyapatite, refers to a calcium phosphate-based coating applied to the femoral hip stem of interest in this study; MoM: Metal-on-metal, refers to the bearing materials of the ball and socket joint of the artificial hip; MoP: Metal-on-polyethylene, refers to the bearing materials of the ball and socket joint of the artificial hip; SD: Standard deviation, the average difference between individual values and the group mean; THA: Total hip arthroplasty, refers to the surgery of replacing a person's hip joint with artificial components

\section{Acknowledgements}

The authors would like to thank Mr. Kieran Derksen for his contribution to this study in the form of retrieval analysis and data collection.

\section{Authors' contributions}

TG assisted in developing the study plan, performed the data analysis, and wrote the majority of the manuscript. BF assisted in conceptualizing the study, assisted in the clinical interpretation of results, and wrote significant portions of the manuscript. TT contributed the implant retrieval knowledge, guided the statistical analysis, and contributed significantly to the manuscript. CB identified the initial cases of implant failure, conceptualized the study, provided the clinical perspective and experience with the study devices, and contributed significantly to the manuscript. All authors reviewed, revised, and approved the final manuscript.

\section{Funding}

Study funding was provided by the Manitoba Medical Services Foundation and the Department of Surgery at the University of Manitoba.

\section{Availability of data and materials}

The dataset generated from this study is available from the corresponding author on reasonable request.

\section{Ethics approval and consent to participate}

Patients were not directly consented for their inclusion into this research as it is a retrospective study. All patients involved in this study provided their consent to have their clinical data stored in our research database at the time of surgery and used for subsequent retrospective-type research. Research ethics approval for the present study was granted by the local review board (H2013:325, University of Manitoba).

\section{Consent for publication}

All authors provide their consent to have this research published. No identifying patient data is contained within, and therefore, no patient consent for publication was obtained.

\section{Competing interests}

Institutional research and educational funding has been received from DePuy-Synthes in the past 5 years. $C B, T$, and $T G$ are participating in one or more ongoing clinical studies with DePuy-Synthes products. CB and TG have received expense reimbursement for a presentation involving DePuy-Synthes products. TG has signed a consultancy agreement with DePuy-Synthes but receives no financial benefit. The other author declares that there are no competing interests.

\section{Author details}

'Orthopaedic Innovation Centre, 320-1155 Concordia Avenue, Winnipeg R2K2M9, Manitoba, Canada. ${ }^{2}$ Concordia Joint Replacement Group, 310-1155 Concordia Avenue, Winnipeg, Manitoba R2K 2M9, Canada. ${ }^{3}$ Department of Surgery, University of Manitoba, Winnipeg, Manitoba, Canada.

\section{Received: 2 April 2019 Accepted: 8 July 2019}

\section{Published online: 19 July 2019}

\section{References}

1. Dumbleton J, Manley MT. Hydroxyapatite-coated prostheses in total hip and knee arthroplasty. J Bone Joint Surg Am. 2004;86-A(11):2526-40.
2. Guardia C, et al. Roseland(R) prosthesis: quality of life's studies about 68 patients with a mean followed-up of 43.8 months. Chir Main. 2010;29(5): 301-6.

3. Elias JJ, et al. Medial cortex strain distribution during noncemented total hip arthroplasty. Clin Orthop Relat Res. 2000;370:250-8.

4. Herrera A, et al. Cementless hydroxyapatite coated hip prostheses. Biomed Res Int. 2015;2015:386461.

5. Tudor FS, et al. Long-term comparison of porous versus hydroxyapatite coated sleeve of a modular cementless femoral stem (SROM) in primary total hip arthroplasty. J Arthroplast. 2015;30(10):1777-80.

6. Davda K, et al. An analysis of metal ion levels in the joint fluid of symptomatic patients with metal-on-metal hip replacements. J Bone Joint Surg Br. 2011;93(6):738-45.

7. Pandit $\mathrm{H}$, et al. Pseudotumours associated with metal-on-metal hip resurfacings. J Bone Joint Surg Br. 2008:90(7):847-51.

8. Browne JA, et al. Failed metal-on-metal hip arthroplasties: a spectrum of clinical presentations and operative findings. Clin Orthop Relat Res. 2010; 468(9):2313-20.

9. Whitehouse MR, et al. Adverse local tissue reactions in metal-onpolyethylene total hip arthroplasty due to trunnion corrosion: the risk of misdiagnosis. Bone Joint J. 2015;97-B(8):1024-30.

10. Shah KM, Wilkinson JM, Gartland A. Cobalt and chromium exposure affects osteoblast function and impairs the mineralization of prosthesis surfaces in vitro. J Orthop Res. 2015;33(11):1663-70.

11. Mabilleau G, et al. Cobalt, chromium and nickel affect hydroxyapatite crystal growth in vitro. Acta Biomater. 2010;6(4):1555-60.

12. AOANJRR. National joint replacement registry: metal on metal bearing surface total conventional hip arthroplasty. Adelaide: Australian Orthopaedic Association; 2015.

13. NJR, National Joint Registry for England, Wales, Northern Ireland and the Isle of Man: 13th Annual Report. 2016.

14. Gruen TA, McNeice GM, Amstutz HC. "Modes of failure" of cemented stemtype femoral components: a radiographic analysis of loosening. Clin Orthop Relat Res. 1979;141:17-27.

15. Goldberg JR, et al. A multicenter retrieval study of the taper interfaces of modular hip prostheses. Clin Orthop Relat Res. 2002:401:149-61.

16. ASTM F3129-16. Standard Guide for Characterization of Material Loss from Conical Taper Junctions in Total Joint Prostheses. West Conshohocken: American Society of Testing and Materials International; 2016.

17. Lord JK, Langton DJ, Nargol AVF, Joyce TJ. Volumetric wear assessment of failed metal-on-metal hip resurfacing prostheses. Wear. 2011;(272):79-87.

18. Ulrich SD, et al. Total hip arthroplasties: what are the reasons for revision? Int Orthop. 2008;32(5):597-604.

19. Liudahl AA, et al. Metal on metal total hip arthroplasty using modular acetabular shells. J Arthroplast. 2013;28(5):867-71.

20. Barrett WP, Kindsfater KA, Lesko JP. Large-diameter modular metal-on-metal total hip arthroplasty: incidence of revision for adverse reaction to metallic debris. J Arthroplast. 2012:27(6):976-83 e1.

21. Bernasek $T L$, et al. Five- to ten-year outcomes for modular metal-on-metal total hip arthroplasty. J Arthroplast. 2013;28(7):1231-4.

22. Kindsfater KA, et al. Minimum 5-year results of modular metal-on-metal total hip arthroplasty. J Arthroplast. 2012;27(4):545-50.

23. Atrey A, et al. 601 metal-on-metal total hip replacements with $36 \mathrm{~mm}$ heads a 5 minimum year follow up: levels of ARMD remain low despite a comprehensive screening program. J Orthop. 2017;14(1):108-14.

24. Matharu GS, et al. Outcomes of a metal-on-metal total hip replacement system. Ann R Coll Surg Engl. 2014;96(7):530-5.

25. Langton DJ, et al. Retrospective cohort study of the performance of the Pinnacle metal on metal (MoM) total hip replacement: a single-centre investigation in combination with the findings of a national retrieval centre. BMJ Open. 2016;6(4):e007847.

26. Lainiala $\mathrm{O}$, et al. Adverse reaction to metal debris is more common in patients following MoM total hip replacement with a $36 \mathrm{~mm}$ femoral head than previously thought: results from a modern MoM follow-up programme. Bone Joint J. 2014:96-B(12):1610-7.

27. Hallan G, et al. Medium- and long-term performance of 11,516 uncemented primary femoral stems from the Norwegian arthroplasty register. J Bone Joint Surg Br. 2007;89(12):1574-80.

28. Vidalain JP. Twenty-year results of the cementless Corail stem. Int Orthop. 2011;35(2):189-94. 
29. Buttaro MA, et al. Metaphyseal debonding of the Corail collarless cementless stem: report of 18 cases and case-control study. Bone Joint J. 2017;99-B(1 1):1435-41.

30. Gilbert JL, Buckley CA, Jacobs JJ. In vivo corrosion of modular hip prosthesis components in mixed and similar metal combinations. The effect of crevice, stress, motion, and alloy coupling. J Biomed Mater Res. 1993;27(12):1533-44.

31. Higgs $G B$, et al. Does taper size have an effect on taper damage in retrieved metal-on-polyethylene total hip devices? J Arthroplast. 2016;31(9 Suppl):277-81.

32. Del Balso C, et al. Trunnionosis: does head size affect fretting and corrosion in total hip arthroplasty? J Arthroplast. 2016;31(10):2332-6.

33. Del Balso C, et al. Taperosis: does head length affect fretting and corrosion in total hip arthroplasty? Bone Joint J. 2015;97-B(7):911-6.

34. Porter DA, et al. Modern trunnions are more flexible: a mechanical analysis of THA taper designs. Clin Orthop Relat Res. 2014:472(12):3963-70.

35. MacLeod AR, et al. Large-diameter total hip arthroplasty modular heads require greater assembly forces for initial stability. Bone Joint Res. 2016;5(8):338-46

36. Esposito $\mathrm{Cl}$, et al. What is the trouble with trunnions? Clin Orthop Relat Res. 2014;472(12):3652-8

37. Brock TM, et al. Shorter, rough trunnion surfaces are associated with higher taper wear rates than longer, smooth trunnion surfaces in a contemporary large head metal-on-metal total hip arthroplasty system. J Orthop Res. 2015; 33(12):1868-74.

38. Bauer TW, et al. Hydroxyapatite-coated femoral stems. Histological analysis of components retrieved at autopsy. J Bone Joint Surg Am. 1991;73(10):1439-52

39. Lee $\mathrm{SH}$, et al. Human monocyte/macrophage response to cobalt-chromium corrosion products and titanium particles in patients with total joint replacements. J Orthop Res. 1997;15(1):40-9.

40. Jacobs JJ, Hallab NJ. Loosening and osteolysis associated with metal-onmetal bearings: a local effect of metal hypersensitivity? J Bone Joint Surg Am. 2006;88(6):1171-2

41. Dawes C. What is the critical pH and why does a tooth dissolve in acid? J Can Dent Assoc. 2003;69(11):722-4.

42. Milosev I, et al. pH and metal concentration of synovial fluid of osteoarthritic joints and joints with metal replacements. J Biomed Mater Res B Appl Biomater. 2016;105(8):2507-15.

43. Willert $\mathrm{HG}$, et al. Crevice corrosion of cemented titanium alloy stems in total hip replacements. Clin Orthop Relat Res. 1996;333:51-75.

44. Pilliar RM, Lee JM, Maniatopoulos C. Observations on the effect of movement on bone ingrowth into porous-surfaced implants. Clin Orthop Relat Res. 1986;208:108-13.

45. Angadji A, et al. Influence of cup orientation on the wear performance of metal-on-metal hip replacements. Proc Inst Mech Eng H. 2009;223(4):449-57.

46. Reinisch $\mathrm{G}$, et al. Retrieval study of uncemented metal-metal hip prostheses revised for early loosening. Biomaterials. 2003;24(6):1081-91.

47. Langton DJ, et al. Accelerating failure rate of the ASR total hip replacement. J Bone Joint Surg Br. 2011;93(8):1011-6.

48. Engh CA Jr, Ho H, Padgett DE. The surgical options and clinical evidence for treatment of wear or corrosion occurring with THA or TKA. Clin Orthop Relat Res. 2014;472(12):3674-86.

\section{Publisher's Note}

Springer Nature remains neutral with regard to jurisdictional claims in published maps and institutional affiliations.

Ready to submit your research? Choose BMC and benefit from:

- fast, convenient online submission

- thorough peer review by experienced researchers in your field

- rapid publication on acceptance

- support for research data, including large and complex data types

- gold Open Access which fosters wider collaboration and increased citations

- maximum visibility for your research: over $100 \mathrm{M}$ website views per year

At BMC, research is always in progress.

Learn more biomedcentral.com/submissions 